\title{
ARAH PERKEMBANGAN TEKNOLOGI SISTEM INFORMASI GEOGRAFI DI INDONESIA
}

\author{
Oleh : Suharto Widjojo \\ Suharjo
}

\section{$\overline{\text { ABSTRACT }}$}

In the next decade, technology of geographic information system should realize the vast advance continuously. The advance is getting visible in velocity, storing capacity and computation system. The role of information system which is oriented on spatial or earth surface will dominantly influence to confirming decision and operating the long-drawn-out development which is environmental sight minded.

There are many handicap and expectations to confront the development of spatial information needed in confirming decision. This proposal tries to analize some of the expectation and threaten against the advance of information system.

\section{ABSTRAK}

Pada dekade mendatang, teknologi sistem informasi geografik terus berkembang dengan cepat. perkembangan akan semakin nampak pada kecepatan, kapasitas penyimpanan dan sistem komputasi. Peranan sistem informasi yang berorientasi pada referensi dipermukaan bumi atau spasial akan semakin dominan dalam pengambilan keputusan untuk perencanaan dan operasionalisasi pembangunan yang berkelanjutan dan berwawasan lingkungan.

Banyak tantangan dan harapan yang perlu dihadapi dalam perkembangan informasi spasial yang diperlukan dalam pengambilan keputusan. Makalah ini mencoba mengulas beberapa harapan dan kendala atau tantangan dalam perkembangan sistem informasi geografik di Indonesia.

\section{PENDAHULUAN}

Era informasi tergantung teknologi yang dikembangkan manusia. Perkiraan, janji dan visi tentang dunia melalui teknologi memenuhi banyak program seminar atau pertemuan ilmiah lainnya selama bertahun-tahun. Tetapi hampir setiap pembicaraan tentang perkembangan dan kemajuan teknologi, seperti teknologi sistem informasi geografik (SIG), penuh dengan kesulitan dan tantangan.

Pada dekade mendatang peranan SIG akan terus semakin menonjol, sebab pengambilan keputusan terutama dalam bidang informasi spasial dan geometrik akan semakin berperanan dan dominan. Dalam be- 
berapa hal pengambilan keputusan dapat mempengaruhi efektifitas dan kelangsungan bisnis, pemerintah dan institusi lainnya. Kualitas dan efektifitas pengambilan keputusan tentang ling kungan mempunyai dampak yang besar dalam ekosistem, kualitas hidup dan persamaan sosial untuk masa sekarang dan yang akan datang. Keputusan yang dapat didukung oleh SIG dapat berupa manajemen harian sampai keputusan untuk kebijakan politis oleh pemerintahan pusat, daerah atau perusahaan swasta.

SIG mempunyai aplikasi yang beragam dan akan terus berkembang sesuai dengan perkembangan perangkat lunak dan perangkat kerasnya. Penemuan baru dalam bidang SIG berarti lebih intensif komputasi, mudah dioperasikan dengan perangkat keras yang semakin kecil, handal dengan harga yang relatif lebih mahal. Perkembangan penyimpanan data juga cukup dramatis. Sekitar pertengahan 1980an, kebanyakan kapasitas penyimpanan masih dalam hitungan $\mathrm{MB}$, tetapi sekarang sudah mencapai GB, untuk drive. Kecenderungan penambahan kecepatan dan penambahan kapasitas penyimpanan tanpa pe rubahan harga, merupakan tujuan SIG untuk periode mendatang.

SIG adalah proses bukan produk. Meskipun teknologi SIG mudah dibeli, diperoleh dan digunakan, mengem bangkan SIG dalam suatu organisasi perlu perencanaan, terutama untuk konversi data manual ke digital dan kemudian mengembangkan prosedur yang efektif untuk mengelola database (crane, 1993). Lebih lanjut Jacub Rais ,1994 menekankan bahwa teknologi dapat dibeli dalam satu malam apabila tersedia dana, tetapi sumber daya manusia, mekanisme,koordinasi, struk tur organisasi, perawatan, standart data, keterbukaan dean lain-lain perlu adaptasi dengan teknologi SIG tersebut.

Makalah ini mencoba mengulas SIG dalam dukungannya terhadap pengambilan keputusan, standart, kualitas data, pendidikan dan tantangan SIG di Indonesia di masa yang akan datang.

\section{INFORMASI SPASIAL}

SIG merupakan informasi yang berreferensi terhadap koordinat di permukaan bumi yang diterapkan untuk mengelola informasi spasial yang dapat digunakan oleh perencana, analis, pembuat keputusan dan lainlain. Karena informasi hanya akan berguna apabila dapat dimanfaatkan seperti perencanaan, pengambilan keputusan, maka informasi yang tersedia haruis akurat, berguna, up-to-date dan sesuai untuk tujuan tersebut (Baker \& McLaughin, 1991).

Komponen informasi cukup dominan dalam informasi spasial yang mempunyai tiga dimensi, bujur, lintang dan tinggi serta dimensi keempat yaitu waktu. Informasi spa- 
sial dapat berupa fakta, data mentah hasil pengukuran, data turunan atau mungkin pengetahuan hasil kesimpulan dari fakta dan data. Lebih jauh informasi mungkin berupa hasil analisis fakta dan data dalam disiplin ilmu tertentu.

Ada beberapa informasi non spasial yang relevan dalam konteks data spasial. Yang paling nyata adalah atribut data yang secara.langsung menjelaskan data titik, garis, atau poligon dari obyek spasial tertentu. Yang menjadi penting pada periode sekarang dalam informasi non spasial adalah metainformasi yang menjelaskan annotasi, karakteristik data dan informasi. Jadi meta informasi belum berhubungan langsung dengan data di permukaan bumi tetapi hanya sebagai informasi tentang keberadaan data. Sebagai contoh meta informasi adalah bagaimana mendapatkan data, lokasi data, kualitas, validitas, akurasi dan sebagainya (Baker \& Mvlaughin, 1991).

\section{INFROMASI SPASIAL DA- LAM DUKUNGANNYA TER- HADAP PENGAMBILAN KE- PUTUSAN}

Salah satu tantangan terbesar Penerapan SIG adalah dalam bidang manajemen lingkungan, kebanyakan teknologi SIG diterapkan untuk Inventarisasi sumberdaya alam, sistem informasi lahan, analisis demografi dll. Aplikasi infromasi spasial dalam dukungannya dalam pengam- bilan keputusan merupakan tujuan dari teknologi SIG. Meskipun keputusan yang diambil bervariasi dari sederhana sampai keputusan penting dan tingkat efektifitas SIG dalam mendukung keputusan tentu bervariasi (Goodchild, 1993).

Aplikasi SIG dalam mendukung Pembuatan Keputusan untuk mengelola lingkungan akan memerlukan pertanyaan baru tentang kemampuan SIG agar tersedia bagi pengguna data (users) yang bukan spesialis di bidang analisis spasial. Pada periode mendatang, SIG akan lebih sering digunakan dalam hubungannya dengan aplikasi perangkat lunak komputer, untuk menemukan hubungan dan pola antar informasi yang bervariasi tujuannya untuk mendapatkan pan dangan baru dan melakukan sintesis pengetahuan baru, untuk pengelolaan dalam bidang sumber daya alam dan lingkungan (Baker \& Mclaughin, 1991).

SIG akan semakin populer sebagai pendukung kebijakan, terutama disektor pemerintahan. Kemampuan teknologi SIG untuk membuat keputusan dengan jaringan network, akan mengurangi biaya dan waktu untuk membuat keputusan bersama dan tentu saja akan mengurangi atau menghilangkan duplikasi atau perbedaan keputusan tentang subjek atau areal yang sama. Kerjasama antar pengguna data yang semakin baik akan memungkinkan penggabungan 
data yang lebih baik dan berperanan dalam pembuatan keputusan.

Lebih mendasar, SIG dan data spasial lainnya, akan lebih mudah menghindari kendala yang mengikuti pemikiran bahwa SIG sebagai wadah daripada peta. Layer (lapisan) database dibuat dengan digitasi dari peta. Tetapi peta mewakili data secara statis dan data di alam cenderung berubah seirama dengan perubahan waktu. Apabila peta adalah hasil akhir dari proses kartografi, Database adalah hasil akhir dari SIG. Perkembangan baru adalah database yang berorientasi obyek, temporal SIG dan analisis spasial yang menuju konsep database spasial yang fleksibel.

Pada periode mendatang tersebut akan banyak permintaan untuk pembuatan model sistem ekologik baik untuk skala lokal, regional maupun nasional. Model tersebut harus memperoleh sistem dinamis dari lingkungan ekosistem dan menjelaskan hubungan antara faktor sosialekonomik dengan lingkungan. Seirama dengan perkembangan modellings, kemampuan untuk publikasi informasi lingkungan untuk pengguna yang bervariasi akan banyak diminati dan perlu perhatian serius.

\section{$\overline{\text { STANDARD DATA }}$}

Pada periode sekarang lebih banyak usulan dan pembicaraan tentang pelaksanaan standard data, sehingga standard data perlu diberikan prioritas penanganannya untuk mendukung integritas sistem. Pengembangan data base akan dipercepat dengan adanya standard data. Data format standard akan sangat menolong, dan akan mengurangi waktu dalam transfer dan reformat data dari satu sistem database ke sistem lainnya.

Selain standard data, yang lebih penting dalam pembuatan keputusan untuk jangka panjang adalah data akses, dan kemampuan pengguna data untuk mencari (Search) dan menemukan data yang memenuhi kriteria kebutuhannya. Komunikasi networks dan network server akan membantu untuk mengembangkan akses, standard data dan media data. Harapan penulis meta data di Indonesia akan tersedia untuk publik sebelum akhir dekade ini. Apabila data yang ada tidak dapat diakses oleh users lain. maka SIG di Indonesia akan menjadi proyek yang mahal atau hanya alat untuk demo.

\section{$\overline{\text { PENDIDIKAN }}$}

Pendidikan atau pengembangan sumberdaya manusia dalam bidang SIG masih perlu dikembangkan. Sampai dengan pertengahan tahun 1990 an ini belum banyak perguruan tinggi di Indonesia yang secara eksplisit mengajarkan SIG sebagai kurikulum. Walau didunia pelajaran SIG sudah ditanamkan lebih dari 500 
universitas dan akademi (Goodchil, 1993) tetapi di Indonesia SIG baru diajarkan di be berapa Universitas baik negeri maupun swasta.

Meskipun SIG terlihat sebagai hal yang cukup menarik untuk menambah kemampuan dalam hal pemecahan masalah, studi lingkungan, konsep spasial dan lain-lain, masalah bahan material untuk pengajaran masih dirasa kurang. Sampai saat ini belum tersedia buku teks tentang SIG berbahasa Indonesia yang dapat dijadikan buku pegangan para pengajar.

\section{$\overline{\text { KUALITAS DATA }}$}

Salah satu faktor yang mem pengaruhi kualitas data adalah kesalahan. Kesalahan selalu terjadi pada setiap tahap dalam proses generalisasi dan penerapan SIG. Dari pengumpulan data sampai interpretasi hasil secara menyeluruh memungkinkan terjadinya kesalahan. Maksud membicarakan kesalahan bukan untuk menghilangkan, tetapi untuk mengu rangi kesalahan tersebut sehingga menambah kualitas data (Aronoff, 1989). Mendapatkan kesalahan yang paling kecil, kemungkinan besar akan

\section{Beberapa sumber kesalahan dalam SIG}

$\begin{array}{ll}\text { Tahap } & \text { Sumber kesalahan } \\ \text { Pengumpulan data } & \text { Kesalahan dalam pengumpulan data } \\ & \text { Kesalahan dalam peta yang tersedia yang digunakan sebagai } \\ \text { sumberdata } & \text { Kesalahan dalam analis data penginderaan jauh } \\ \text { Kasukan data } & \text { Kurang akurasi dalam digitasi disebabkan oleh alat dan operator } \\ & \text { Kesalahan dalam kenampakan geografis (batas antar unit tidak jelas) } \\ \text { Penyimpanan data } & \text { Tidak sesuai presisi numerik } \\ & \text { Tidak sesuai presisi spasial } \\ \text { Manipulasi data } & \text { Klas interval tidak sesuai dengan kebutuhan } \\ & \text { Kesalahan batas } \\ & \text { Kesalahan akibat multi overlay } \\ & \text { Adanya sliver poligon dalam prosedur overlay. } \\ & \text { Skala kurang akurat } \\ & \text { Kesalahan karena faktor peralatan media output. } \\ \text { kesalahan karena media yang tidak stabil } & \text { Informasi kurang dimengerti dengan jelas } \\ \text { Keluaran data } & \text { Informasi mungkin tidak sesuai penggunaannya. }\end{array}$

Sumber : Aronoff, 1989 
mendapatkan kualitas yang paling bagus, tetapi bukan berarti pendekatan yang paling efektif.

Tahap kesalahan dalam SIG perlu dikelola, sehingga kesalahan tersebut tidak akan membuat cacat/invalid tentang informasi yang dihasilkan oleh sistem. Tabel 1 menunjukkan kesalah an-kesalahan yang mungkin terjadi dari pengumpulan data, masukan data, penyimpanan data, keluaran data sampai penggunaan data.

Apabila kesalahan dapat diminimal kan, maka kualitas data akan semakin baik. Tetapi bukan berarti kesalahan yang paling minimal akan meng hasilkan data yang paling efektif untuk tujuan tertentu.

\section{TANTANGAN PENERAPAN SIG DI INDONESIA}

Apabila dilihat dari pengguna SIG di Indonesia, dengan jumlah perangkat keras dan lunaknya teknologi tersebut dapat dikatakan telah operasional dapat telah berfungsi dalam unit organisasi pemilik dan pengguna teknologi tersebut. Tetapi apakah teknologi SIG telah ditetapkan secara optimal dalam mendukung pengelolaan dan pembuatan keputusan di setiap organisasi ? Untuk menjawab pertanyaan tersebut tidaklah mudah. Benar, lebih dari 100 (seratus) perangkat keras dan perang kat lunak SIG dioperasikan di Indonesia, tetapi sebagian besar masih berorientasi kepada proyek atau unit organisasi.

\section{Sembilan Prinsip SIG}

Prinsip 1 SIG adalah sistem informasi data base.

Prinsip 2 SIG dan peta perlu dikelola.

Prinsip 3 SIG paling berguna apabila referensi geografik dicatat secara konsisten dalam sistem koordinat yang kontinyu.

Prinsip 4 SIG mempunyai topologi.

Prinsip 5 SIG mempunyai banyak pengguna dan sebaiknya digunakan secara multi disiplin.

Prinsip 6 Perangkat lunak dan perangkat keras selalu berubah yang bertujuan menambah fungsinya

Prinsip 7 SIG berkembang terus dalam hal teknologi, biaya dan perlu dukunga administratif. Karena itu perlu komitmen jangka panjang untuk mencapai sukses.

Prinsip 8 SIG menyebabkan perubahan dalam prosedur, operasi, penataan institusional antar users.

Prinsip $9 \quad$ Kader yang dilatih, terdidik, memotivasi dan berdedikasi penting untuk suksesnya program SIG (Crane, 1993). 
Kemudian memperoleh data, pembaharuan yang terus menerus, standard interchange format, masih merupakan tantangan yang perlu dijawab dengan kerja keras.

Lebih lanjut kemudahan mem peroleh data digital atau pertukaran data antar instansi atau antara data producer dengan customer belum diatur secara transparant. Sehingga tidak menutup kemungkinan data digital yang sudah dimiliki suatu informasi, masih perlu didigit lagi oleh pengguna lain karena data digital tersebut belum/tidak memungkinkan untuk ditransfer kepada pengguna lain. Apabila hal semacam ini terjadi maka SIG merupakan teknologi yang mahal. Untuk menjawab tantangan SIG di masa depan, perlu dikenalkan dan disebarkan sembilan prinsip SIG, agar dicapai hasil yang optimal. Sembilan prinsip SIG tersebut dapat dilihat dalam tabel 2 .
Apabila kesembilan prinsip SIG dapat dimanfaatkan oleh semua pengguna SIG di Indonesia, maka per kembangan SIG akan semakin maju dan SIG akan benar-benar operasional di Indonesia.

\section{$\overline{\text { PENUTUP }}$}

SIG di Indonesia telah digunakan oleh banyak instansi baik pemerintah maupun swasta untuk mendukung perencanaan dan pembuatan keputusan dalam unit organisasinya.

SIG masih mempunyai beberapa hal yang perlu dikembangkan seperti standard data, pendidikan, kualitas data dan sebagainya, agar diperoleh hasil yang optimal. Kesembilan prinsip SIG perlu dikenalkan kepada peng guna SIG pada semua tingkatan agar diperoleh kesamaan bahasa dalam mengoperasionalkan SIG sehingga SIG akan semakin berguna bagi pembangunan nasional. 


\section{REFERENSI}

Aronoff, S, Geographical Information Systems : A Management Perspective : Ottawa: WDL Publucations, 1989.

Baker, D. and John McLaughin, Geomatics 2000-toward the spatial Information Marketplace of the next Decade, AURISA 91, Wellington, New Zealand 19-22 November 1991.

Crane, D. E, Future Directions for Geographic Information System, AURISA 93, Adelaide, South Australia, 21-26 November 1993.

Goodchild, M. F, Future Directions : Geographic Information and analysis, AURISA 93, Adelaide, South Australia 21-26 November 1993.

Rais, J, Operational of GIS in Indonesia from data banks concept to GIS Progress and Constraints, Proceeding 3 rd Annual User Conference, ESRI South Asia, Jakarta, 5-6 September 1994. 